\title{
INICIAÇÃO À EDUCAÇÃO POLITÉCNICA EM SAÚDE: UMA PROPOSTA DE FORMAÇÃO DE TÉCNICOS EM SAÚDE
}

\author{
INITIATION TO POLYTECHNIC EDUCATION IN HEALTH: A PROPOSAL TO QUALIFY HEALTH \\ TECHNICIANS
}

\author{
Ana Lúcia de Moura Pontes 1 \\ Angélica Ferreira Fonseca ${ }^{2}$
}

Resumo A Escola Politécnica de Saúde Joaquim Venâncio, da Fundação Oswaldo Cruz (EPSJV/ Fiocruz), tem a politecnia como eixo da sua formação técnica, incorporando também como premissas a pesquisa como princípio educativo e a educação da sensibilidade, dos sentidos e dos sentimentos. Estas premissas, articuladas à concepção de trabalho como princípio educativo, fundamentam um projeto político e pedagógico que luta contra um projeto historicamente hegemônico de formação de trabalhadores. O trabalho relata a experiência de construção do primeiro semestre de formação técnica dos alunos da EPSJV, comum a todas as habilitações técnicas, e que busca desenvolver um conhecimento crítico sobre o campo da saúde, com ênfase na área da saúde pública. Criado em 2002, o Módulo Básico, a primeira estratégia com esse objetivo, passou em 2006 por uma avaliação, transformando-se em Iniciação à Educação Politécnica em Saúde no ano seguinte. Este relato faz também algumas reflexões críticas sobre tal processo.

Palavras-chave educação profissional; reforma curricular; politecnia.
Abstract The Joaquim Venâncio Polytechnic School of Health, which belongs to the Oswaldo Cruz Foundation (EPSJV/Fiocruz), has polytechnics as an axis for its technical formation, also incorporating research as an educational principle and education of sensibility, of the senses, and of feelings as its basic premises. These premises, articulated with the concept of work as an educational principle, are the base for a political and pedagogic project that fights against a historically hegemonic worker qualification project. The article reports on the experience of elaborating a first semester of technical qualification for EPSJV students, common in all technical accreditations, and that seeks to develop critical knowledge about the field of health with emphasis on Public Health. Created in 2002, the Basic Module, the first strategy with this objective, was evaluated in 2006 and turned into the Initiation to Polytechnic Education in Health in the following year. This report also reflected critically on such process.

Keywords professional education; curricular reform; polytechnics. 


\section{Introdução}

A Escola Politécnica de Saúde Joaquim Venâncio, da Fundação Oswaldo Cruz (EPSJV/Fiocruz), tem a politecnia como eixo da sua formação técnica, ou seja, visa que seus alunos "compreendam de forma cada vez mais aprofundada os princípios científicos que estão, direta e indiretamente, na base da forma de se organizar o trabalho na sociedade" (Saviani, 2003, p. 142). Pautada neste conceito, a EPSJV procura incessantemente trazer a politecnia para a atualidade, incorporando premissas como a pesquisa como princípio educativo e a educação da sensibilidade, dos sentidos e dos sentimentos. Estas premissas, articuladas à concepção de trabalho como princípio educativo, fundamentam um projeto político e pedagógico que luta contra um projeto historicamente hegemônico de formação de trabalhadores.

Sob essa orientação busca-se romper com a dualidade tradicional do ensino médio, em que se oferece aos alunos do ensino técnico-profissionalizante uma formação instrumental para o trabalho (Frigotto, Ciavatta e Ramos, 2005). Assim, pretende-se, na EPSJV, que esses alunos tenham acesso aos conhecimentos científicos que estão na base da técnica e que assim sejam capazes de ter uma visão crítica sobre o processo de trabalho em saúde, tornando-se também capazes de atuar no sentido de sua transformação (Pereira e Ramos, 2006). Nesse sentido, colocar em curso essa proposta é coerente com alguns movimentos do campo da educação que buscam fortalecer um "ensino que integre ciência e cultura, humanismo e tecnologia visando o desenvolvimento de todas potencialidades" (Frigotto, Ciavatta e Ramos, 2005, p. 36). Identificamos que o tensionamento entre a perspectiva politécnica e o dualismo perpassam as formulações e reformulações das leis da educação, sendo a própria LDB/96 e o decreto $\mathrm{n}^{0}$ 5.154/2004 exemplos deste processo.

No presente relato pretende-se refletir sobre uma experiência que tem buscado responder à seguinte questão: como efetivar uma formação de trabalhadores de nível técnico no campo da saúde, que assume a saúde como processo, o trabalho e a ciência como eixos e a cultura e a política como dimensões indissociáveis desse processo?

\section{Histórico da experiência}

Em 2002, implementou-se uma proposta denominada Módulo Básico, na qual os alunos das modalidades ensino integrado, subseqüente e concomitante, das quatro habilitações da EPSJV - Gestão, Biodiagnóstico, Vigilância em saúde, Registro e informações -, cursariam durante o primeiro semestre de sua formação um módulo comum de disciplinas. O objetivo naquele momento era fornecer a todos alunos um panorama das questões 
que conformavam o campo da saúde pública e do trabalho em saúde. A premissa da proposta era que todos os alunos deveriam ser capazes de pensar sobre sua prática de trabalho a partir de um contexto mais amplo, expresso pelo Sistema Único de Saúde (SUS), independentemente de suas habilitações técnicas.

Como eixo para fundamentar essa formação, optou-se por desenvolver um conhecimento crítico sobre o campo da saúde, com ênfase na área da saúde pública, por meio de seis disciplinas, compondo uma carga horária de 360 horas, a saber: Trabalho, Educação e Saúde, Meio Ambiente e Processo Saúde-Doença, Políticas de Saúde, Planejamento, Gestão e Saúde, Biossegurança e Comunicação e Informação em Saúde. No plano de curso de 2006, encontram-se definidas as seguintes competências ${ }^{3}$ (conforme registro no MEC) para cada disciplina do Módulo Básico:

1) Trabalho, Educação e Saúde - compreender a dupla dimensão do conceito de trabalho, as determinações sócio-históricas da estruturação dos sistemas de saúde e as funções da escola no modo capitalista de produção;

2) Políticas de Saúde no Brasil - compreender as políticas de saúde no Brasil como um processo histórico, analisando a organização e operacionalização do SUS no contexto atual;

3) Meio Ambiente e Processo Saúde-doença - compreender a relação entre espaço ecológico, espaço relacional, espaço político e saúde, relacionando o ambiente aos fatores determinantes do processo saúde-doença, analisando as mudanças demográficas e epidemiológicas do quadro sanitário brasileiro;

4) Planejamento, Gestão e Saúde - compreender o papel da gestão, articulada com a natureza do SUS, analisando seus aspectos conceituais;

5) Biossegurança - conhecer e aplicar as normas de biossegurança, com o objetivo de controlar os riscos que o trabalho em saúde pode aportar ao meio ambiente e à vida;

6) Informação e Comunicação em Saúde - identificar processos comunicacionais na sociedade, visando à construção das estratégias para a promoção da saúde, identificando o uso potencial e os limites das tecnologias de informação e comunicação e reconhecendo-se como profissional participativo do processo informacional e usuário do produto informacional.

Inicialmente essas disciplinas ocorriam de forma seqüencial, e ao final de cada uma delas havia a realização de uma prova. Esse modelo de avaliação se mostrou inadequado para expressar o processo de aprendizagem por ser excessivamente fragmentado, indicando a necessidade urgente de modificá-lo. Ademais, percebeu-se a importância de incluir elementos pedagógicos que potencializassem a articulação entre os conteúdos teóricos das disciplinas com a realidade do trabalho em saúde, no SUS. Desta forma, a partir de 2004, inseriram-se na grade curricular quatro práticas de trabalho 
de campo em serviços de saúde. A base do trabalho de campo eram roteiros elaborados tendo por referências questões norteadoras das disciplinas. Assim, o processo avaliativo dos alunos foi vinculado à realização desse trabalho e à elaboração de relatórios parciais e finais. Já a avaliação do módulo, pelos alunos, era feita por meio de dois procedimentos: registro escrito e oral, realizado ao final do semestre.

\section{Reflexões acerca do Módulo Básico}

No sentido de aprofundar os procedimentos de avaliação, com vistas a reorientar a organização do Módulo Básico, em 2006 foram realizados alguns encontros com professores e alunos. Os principais resultados revelaram: a) percepções bastante distintas sobre o objetivo dessa etapa formativa; b) fragmentação dos conteúdos; c) grande alternância de docentes nas disciplinas, prejudicando a relação professor-aluno; d) excesso de conteúdo nas disciplinas, havendo uma perda de foco quanto aos saberes prioritários; e) precária articulação entre os conteúdos das disciplinas. A principal crítica dos alunos era referente aos aspectos didáticos das aulas, sobretudo ao uso excessivo de apresentações audiovisuais (uso de slides) e aulas expositivas.

Assim, a coordenação do Módulo Básico, em conjunto com os coordenadores de disciplinas, apontou para a pertinência de implementar algumas alterações decorrentes dos resultados dessa avaliação, envolvendo as dimensões didáticas e de conteúdo, compreendendo que ambas devem ser pensadas em conjunto, dada a indissociabilidade entre conteúdo e forma (Ciavatta, 2006).

Em relação aos aspectos didáticos, o elemento principal era recolocar a relação aluno-professor no centro do processo educacional, entendendo que é a partir do fortalecimento dessa relação que se instituem formas de promover uma postura ativa do aluno e do professor, contribuindo para a compreensão das potencialidades de cada aluno, na interface com os conhecimentos propostos pelo currículo. Assim, as primeiras orientações apontavam para a redução do número de docentes nas disciplinas, revisão do uso de slides e reflexão sobre a dinâmica das aulas.

Em relação aos conteúdos, entendemos que o currículo não se constitui como artefato neutro, mas, ao proceder a uma seleção, priorização e legitimação expressa de conteúdos, se apresenta como instrumento político da prática educacional. Neste sentido, o desafio foi delimitar os conteúdos que seriam, ao mesmo tempo, mais adequados para esse momento inicial da formação e consistentes com o propósito de introduzir o aluno no complexo campo da saúde, no contexto do SUS. 
Outros desafios identificados pelos professores eram o aprimoramento do processo avaliativo e a produção de uma unidade teórico-prática, a partir dos conhecimentos das diferentes disciplinas. Essas duas dimensões estavam relacionadas à realização do trabalho de campo em serviços de saúde.

A construção de uma articulação ensino-serviço deve levar em conta os interesses, visões e rotinas de instituições muito diferentes. Assim, é fundamental uma negociação permanente para que o trabalho de campo ultrapasse a característica de visita ao serviço e se consolide como uma estratégia de ensino-aprendizagem. Compreendido nestes termos, parece-nos mais adequado um processo individualizado por grupos de alunos e por instituição para construção da proposta, na qual os serviços de saúde se percebam como atores desse processo.

Cabe aqui um registro dos principais obstáculos para o desenvolvimento do trabalho de campo no modelo em curso. Isto porque, embora os serviços manifestassem boa receptividade à proposta, viam-se sobrecarregados com as demandas da assistência, o que acarretava certo grau de improviso no momento de realizar a atividade com os alunos. Eventualmente os serviços não contavam com setores ou mesmo profissionais com condições de debater as questões propostas nos roteiros (que eram iguais para todos os grupos e serviços). Também percebia-se que, ao invés de ser uma vivência de pesquisa no espaço do trabalho em saúde, essas idas aos serviços tornavam-se 'palestras nos serviços'. Desse modo, não correspondiam à expectativa de permitir ao aluno uma atitude ativa frente aos temas a serem discutidos, tampouco contribuía para a compreensão do cotidiano e da prática dos serviços.

Quanto à avaliação, percebia-se que ainda que fossem realizadas aulas para preparação das idas aos serviços e para a confecção dos relatórios, persistia um distanciamento no processo de orientação dos professores (nesse caso apenas realizado pelos coordenadores do Módulo Básico), que eram em última instância os responsáveis pela nota final dos alunos. Pode-se dizer que esta avaliação tinha um caráter marcadamente pontual, ao invés de processual, contrariando a perspectiva de formação do curso técnico como um todo. Além disso, a própria experiência de avaliação da aprendizagem sofria de certa diluição no coletivo, na medida em que nenhum dos instrumentos adotados era individual - talvez exceto a argüição pública que tinha por base os temas do relatório. Percebia-se também que alguns alunos tinham grande dificuldade de expor oralmente suas opiniões, fazendo com que o processo de avaliação perdesse sensibilidade para detectar as reais dificuldades e avanços na aprendizagem. Isto apontava também para a necessidade de a escola - seus docentes - proporcionar mecanismos progressivos de superação dessas dificuldades. 
Por todos esses motivos, e entendendo que a avaliação deve fortalecer o processo ensino-aprendizagem, constatou-se a necessidade de rever a direção e as práticas estruturadas no sentido de cumprir esse duplo objetivo - integrar os conteúdos e qualificar a avaliação.

\section{Iniciação à Educação Politécnica em Saúde}

Visando expressar de forma mais clara os objetivos desse primeiro momento da formação técnica, superando uma perspectiva de conteúdos mínimos de habilitações ou grupos de trabalho, propôs-se a mudança da denominação desse conjunto de disciplinas do primeiro semestre dos alunos da EPSJV para Iniciação da Educação Politécnica em Saúde (IEP).

Dessa forma, procurou-se repactuar o entendimento de que o primeiro semestre representa uma estratégia para atingir o objetivo da formação politécnica dos alunos. Portanto, são as bases científicas4, éticas, culturais e políticas do trabalho em saúde que devem direcionar a seleção dos conteúdos das disciplinas.

Também se considerou necessário formular um dispositivo pedagógico (anteriormente representado pelo trabalho de campo nos serviços) que permitisse maior unidade entre os conteúdos das disciplinas e, simultaneamente, a aproximação com um campo de investigação, a partir do qual teríamos elementos concretos do trabalho em saúde, em torno dos quais poder-se-ia apoiar a reflexão.

O processo de ensino-aprendizagem também foi um aspecto importante de discussão. Enfatizou-se a participação do aluno, com maior escuta dos seus interesses, expectativas e vivências. Ademais, tentou-se estruturar uma avaliação de caráter mais processual, de forma a potencializar a aprendizagem do aluno.

Assim, durante o primeiro semestre de 2007, foi realizada uma série de mudanças. A primeira constituiu-se de dinâmicas de grupo por meio da quais se procurou conhecer o perfil e expectativas dos alunos acerca da formação técnica na EPSJV e do trabalho em saúde. Desta forma, percebeu-se que muitos alunos visam, a partir da formação técnica, ao aprofundamento dos conhecimentos no campo da saúde e ao preparo para o ensino superior. Ainda no processo de recepção dos alunos, foi apresentada a proposta do IEP e realizados dois debates tendo como temas 'A pesquisa como princípio educativo' e 'O trabalho e formação do técnico em saúde'. Tentou-se, dessa forma, explicitar algumas concepções que direcionam a educação na EPSJV e, nesse primeiro momento, da formação técnica.

As disciplinas que integravam o Módulo Básico continuaram a compor o IEP, pois entende-se que os conhecimentos que as constituem são rele- 
vantes para que trabalhadores da saúde compreendam as determinações sócio-históricas do trabalho e especificamente do trabalho em saúde. Situam-se ainda, como questões nucleares da formação politécnica em saúde, o entendimento da dimensão histórico-social do processo saúdedoença, assim como a construção do campo da saúde e das políticas de saúde no Brasil, com destaque para a consolidação do SUS.

Outro eixo que perpassa a nova proposta é a inserção ativa dos alunos no processo de produção e sistematização de conhecimento pertinente ao campo da saúde. Dessa forma, buscando fortalecer metodologias participativas de ensino-aprendizagem e a pesquisa como princípio educativo, implantou-se um novo dispositivo de ensino-aprendizagem denominado Trabalho de Integração (TI).

O TI consiste na formulação de um processo de prática investigativa, apoiada por um trabalho de campo, sob orientação docente, que busca ampliar os cenários de ensino-aprendizagem dos alunos. Retomam-se aqui os objetivos de problematizar e articular os conteúdos das disciplinas que compõem o IEP (Trabalho, Educação e Saúde, Políticas de Saúde no Brasil, Biossegurança, Meio Ambiente e Processo Saúde-doença, Informação e Comunicação em saúde, e Planejamento, Gestão e Saúde).

Concretamente, o TI é uma atividade de grupo, na qual sete alunos são orientados por dois preceptores. No primeiro semestre de 2007, foram realizados 13 encontros de três horas de duração, com cada um dos nove grupos. Os temas desenvolvidos foram: 1) Ciência e a Fiocruz; 2) Acesso ao SUS: Porta de Entrada Hospital da Lagoa; 3) Saúde Mental; 4) Doação e Transplantes de Órgãos e Tecidos; 5) Saúde da Mulher; 6) Despoluição da Baía de Guanabara; 7) O Trabalho do Agente Comunitário de Saúde; 8) HIV/Aids; 9) Ambulatório do Hospital Geral de Bonsucesso e sua Articulação com a Rede de Serviços do SUS.

O trabalho em pequenos grupos visa também a proporcionar um acompanhamento mais próximo do desenvolvimento do aluno, enfatizando o caráter processual da avaliação, que, por possibilitar um reconhecimento do percurso de aprendizagem de cada aluno, conforma-se em um mecanismo de potencialização desse processo.

Nessas atividades de grupo, desenvolveram-se discussões teóricas, aliadas à apresentação e debate de filmes; trabalhos de campo em organizações do setor saúde (governamentais e não-governamentais), associados a práticas de entrevistas (gestores, profissionais, usuários, estudantes); levantamento de dados em fontes diversas, com destaque para os bancos de dados da saúde, periódicos científicos, sítios eletrônicos e jornais. Objetivou-se, assim, aproximar os alunos das diversas formas de produção de conhecimento, rompendo com uma visão tradicional de ciência, valorizando-se também as dimensões culturais, éticas e políticas da produção do conheci- 
mento. Desta forma, a própria experiência do trabalho de grupo, a troca de idéias e o uso de diversas formas de expressão foram estimulados. Como resultado, quatro grupos trabalharam com a produção de vídeo para apresentação do seminário final5.

Independentemente dos temas, cada preceptor se preocupou em retomar conteúdos discutidos nos módulos teóricos (políticas, informação, gestão, meio ambiente e processo saúde-doença, biossegurança, trabalho, educação e saúde).

Cada aluno desenvolveu, durante o semestre, vários relatórios ou resenhas individuais, para compor a avaliação, fortalecendo a capacidade de sistematizar conhecimentos e expressá-los pela escrita. Os grupos produziram um relatório final, tendo sido previsto um momento para a troca de experiências e avaliação, no qual cada grupo apresentou, de forma livre, o trabalho desenvolvido durante o semestre.

Concluída essa primeira experiência, avalia-se que foi possível avançar em algumas dimensões dessa formação inicial dos técnicos em saúde. Primeiramente, a atividade de TI provocou uma maior proximidade e envolvimento dos docentes com a formação dos alunos. A relação professoraluno apresentou nova configuração como decorrência do trabalho regular e prolongado com os alunos, no qual houve o fortalecimento de relações de afeto, confiança e do diálogo no processo de ensino-aprendizagem. Como decorrência disso, a avaliação dos alunos conseguiu incorporar aspectos objetivos como freqüência, definição das dificuldades de cada aluno e aspectos subjetivos quanto ao desempenho e capacidade de cada aluno. Pela primeira vez, realizou-se uma reunião com coordenadores de disciplinas, docentes e preceptores de TI, na qual se discutiram a participação e o desempenho de cada aluno durante o semestre nos diversos momentos da formação.

Foi aplicado um questionário a fim de obter dados sobre a percepção dos alunos acerca do cumprimento dos objetivos das atividades, da utilidade dos textos de apoio e da qualidade da relação com os docentes. Com a proposta de ter uma abordagem com caráter qualitativo da avaliação sobre o IEP, os alunos desenvolveram textos em grupo. Os resultados desta análise nos indicaram que o aspecto didático-pedagógico permanece como maior desafio dos docentes das disciplinas do IEP.

Durante o seminário de apresentação dos trabalhos de integração, observou-se que essa estratégia foi bem-sucedida para envolver os alunos ativamente no processo de aprendizagem, tendo sido observada uma boa capacidade de articular reflexões em torno do tema desenvolvido no grupo.

A elaboração de textos mostrou-se como uma dificuldade dos alunos, indicando a necessidade de criação de espaços para aprofundar a leitura crítica e a produção escrita, assim como de outras linguagens. 
O uso de diversos recursos midiáticos, principalmente a produção de vídeos, esteve bastante presente nos seminários finais. A utilização desse recurso mostrou ter um grande potencial para estimular a criatividade, a iniciativa e a sensibilidade dos alunos. Além do mais, percebeu-se que o processo de edição dos vídeos se configura como uma etapa do trabalho na qual os alunos se aprofundam no debate dos conteúdos dos temas, por meio da repetida apreciação dos dados e da seleção de cenas para os vídeos. Os aspectos estéticos também se mostraram presentes no processo, assim como o aprendizado do trabalho coletivo. A produção de vídeos apresentou um resultado inesperado, mas extremamente rico em diversas dimensões, podendo ser, até mesmo, considerado um material didático a ser utilizado em outros momentos da formação e na disseminação do conhecimento. Outro produto foi a elaboração de cartilhas sobre o SUS, que serão 'retrabalhadas' pela Coordenação de Comunicação da EPSJV, a fim de serem utilizadas em outros espaços, inclusive nos serviços de saúde visitados pelos alunos.

Por meio do TI, os alunos puderam entrar em contato com a realidade de saúde da população e dos serviços, bem como dialogar com diversos profissionais de saúde e usuários dos serviços. De alguma forma, conheceram algumas dimensões do campo da saúde, nas dimensões da pesquisa e assistência. Entretanto, o interesse de avançar ainda mais na relação teoria-prática, questão propulsora das primeiras reformulações do Módulo Básico - atual IEP -, nos mantém alerta quanto à necessidade de dar continuidade ao processo de avaliar e reformular o processo ensinoaprendizagem.

\section{Considerações finais}

Como considerações finais, e ao mesmo tempo sempre provisórias (pois é essa a condição da educação), reafirmamos o compromisso com a relação entre escola e serviços de saúde, de maneira a vislumbrar a apreensão do processo de trabalho em saúde e a transformação do existente. Isso só poderá ser alcançado se as ciências da natureza, as ciências humanas, as diversas formas da arte caminharem juntas, sem hierarquia de saberes, o que significa um projeto de construção coletiva e solidária de todos os grupos de trabalho da EPSJV.

Também podemos apontar que a reformulação do Módulo Básico e a implementação do IEP têm exigido uma maior reflexão dos docentes sobre suas práticas cotidianas de ensino, assim como das diversas coordenações, num processo contínuo de fortalecimento dos princípios formativos da escola, destacadamente o trabalho e a pesquisa como princípios educativos 
e o compromisso com a formação técnica, ético-política e da educação da sensibilidade e dos sentidos.

\section{Agradecimentos}

Esse relato de experiência foi enriquecido com a leitura crítica e comentários de Isabel Brasil Pereira e Gustavo C. Matta. Também não podemos deixar de agradecer aos professores-pequisadores, profissionais e alunos que se envolveram com o primeiro semestre de Iniciação à Educação Politécnica em Saúde.

\section{Notas}

1 Professora-pesquisadora do Laboratório de Educação Profissional em Atenção em Saúde da Escola Politécnica de Saúde Joaquim Venâncio, da Fundação Oswaldo Cruz (EPSJV/Fiocruz), Rio de Janeiro, Brasil. Mestre em Saúde Pública pela Escola de Saúde Pública Sergio Arouca, da Fundação Oswaldo Cruz (Ensp/Fiocruz). <analupontes@fiocruz.br>

Correspondência: Fundação Oswaldo Cruz, Escola Politécnica de Saúde Joaquim Venâncio, Avenida Brasil, 4.365, Manguinhos, Rio de Janeiro, Brasil, CEP 21040-900.

2 Professora-pesquisadora do Laboratório de Educação Profissional em Atenção em Saúde da Escola Politécnica de Saúde Joaquim Venâncio, da Fundação Oswaldo Cruz (EPSJV/Fiocruz), Rio de Janeiro, Brasil. Mestre em Saúde Pública pela Escola de Saúde Pública Sergio Arouca, da Fundação Oswaldo Cruz (Ensp/Fiocruz). <afonseca@fiocruz.br>

3 Convém ressaltar que a organização do currículo por competências atende à lei vigente. Porém, para a EPSJV, a formação dos trabalhadores da saúde não é pautada para um 'resultado' de aquisição de 'habilidades e atitudes.'

4 A definição do que seriam 'bases científicas' para o campo da saúde não nos parece consensual.

5 A qualidade da produção alcançada pelos os alunos deve-se ao apoio de profissionais do Núcleo de Tecnologias Educacionais (Nuted) da EPSJV, grupo que se mostrou um grande colaborador da proposta. 


\section{Referências}

CIAVATTA, Maria. A questão curricular nos percursos de formação integrada: uma experiência italiana para a reflexão, 2006. Mimeografado.

FRIGOTTO, Gaudêncio; CIAVATTA, Maria; RAMOS, Marise N. A gênese do decreto $\mathrm{n}^{\circ}$ 5154/2004: um debate no contexto controverso da democracia restrita. In: FRIGOTTO et al. (Orgs.). Ensino médio integrado: concepção e contradições. São Paulo: Cortez, 2005. p. 21-56.
PEREIRA, Isabel Brasil; RAMOS, Marise N. Educação profissional em saúde. Rio de Janeiro: Editora Fiocruz, 2006.

SAVIANI, Dermeval. O choque teórico da politécnica. Trabalho, educação e saúde, v. 1, n.1, 2003, p. 131-152

Recebido em 04/09/2007

Aprovado em 22/10/2007 
